This is an electronic reprint of the original article. This reprint may differ from the original in pagination and typographic detail.

Author(s): Vuoskoski, Jonna; Thompson, William F.; Mcllwain, Doris; Eerola, Tuomas

Title: Who enjoys listening to sad music and why?

Year: $\quad 2012$

Version:

Please cite the original version:

Vuoskoski, J., Thompson, W. F., Mcllwain, D., \& Eerola, T. (2012). Who enjoys listening to sad music and why?. Music Perception, 29(3), 311-317.

https://doi.org/10.1525/mp.2012.29.3.311

All material supplied via JYX is protected by copyright and other intellectual property rights, and duplication or sale of all or part of any of the repository collections is not permitted, except that material may be duplicated by you for your research use or educational purposes in electronic or print form. You must obtain permission for any other use. Electronic or print copies may not be offered, whether for sale or otherwise to anyone who is not an authorised user. 


\section{Who Enjoys Listening to Sad Music and Why?}

JONNA K. VUOSKOSKI

University of Jyväskylä, Jyväskylä, Finland

William F. Thompson \& Doris Mcilwain

Macquarie University, Sydney, Australia

Tuomas Eerola

University of Jyväskylä, Jyväskylä, Finland

ALTHOUGH PEOPLE GENERALLY AVOID NEGATIVE EMOTIONAL experiences in general, they often enjoy sadness portrayed in music and other arts. The present study investigated what kinds of subjective emotional experiences are induced in listeners by sad music, and whether the tendency to enjoy sad music is associated with particular personality traits. One hundred forty-eight participants listened to 16 music excerpts and rated their emotional responses. As expected, sadness was the most salient emotion experienced in response to sad excerpts. However, other more positive and complex emotions such as nostalgia, peacefulness, and wonder were also evident. Furthermore, two personality traits - Openness to Experience and Empathy - were associated with liking for sad music and with the intensity of emotional responses induced by sad music, suggesting that aesthetic appreciation and empathetic engagement play a role in the enjoyment of sad music.

Received April 19, 2011, accepted September 14, 2011.

Key words: sadness, music-induced emotions, openness to experience, empathy, preference

$\mathrm{A}$ LTHOUGH PEOPLE AVOID EXPERIENCING NEGATIVE emotions in their daily lives, many people get enormous enjoyment from sad music such as Greensleeves or a Chopin nocturne. The appeal of such music illustrates one of the most intriguing questions in the history of music scholarship: Why do people enjoy listening to music that evokes sadness? The paradox of "pleasurable sadness" has puzzled music scholars for decades (e.g., Levinson, 1997). However, little empirical work has been done to date to document the emotions that listeners actually experience while listening to sad music. Instead, investigations on the topic have mainly been limited to philosophical discussions (e.g., Kivy, 1990; Robinson, 1994).

In a recent questionnaire study, Garrido and Schubert (2011) investigated the role of individual differences in the reported enjoyment of sad music. They found that Absorption (see Tellegen \& Atkinson, 1974) and Music Empathizing (see Kreutz, Schubert, \& Mitchell, 2008) were the best predictors of the enjoyment of sadness-inducing music. They suggested that "dissociation" from pain or displeasure as a cognitive mechanism is at the core of the phenomenon - a conclusion built on a theory proposed by Schubert (1996), according to which an aesthetic context activates a node that inhibits the "displeasure centre" associated with negative emotions, and that feelings of pleasure arise from the mere process of activation. However, their conclusions about the role of dissociation may be premature, as their study design and results leave alternative explanations open. First, they only investigated preference for sadness-inducing music, and not preference for music expressing or eliciting other negative emotions. Thus, we do not know whether the dissociation theory also applies to music expressing anger or fear, for example. Second, they did not investigate what kinds of felt emotions people actually experience in response to sadness-inducing music (or in response to other types of music). This information could prove to be crucial in elucidating why some people enjoy listening to sadness-inducing music.

Investigating the enjoyment of cinematic tragedy, De Wied, Zillmann, and Ordman (1994) discovered that people experiencing more empathic distress during the film also enjoyed the film more than low empathizers did. They suggested that tragedy may inspire a more complex response than just sadness - including positive emotions via the portrayal of close friendship, love, bravery, and human perseverance. Another relevant finding comes from a study by Eerola and Vuoskoski (2011), in which 116 participants evaluated 110 film music excerpts in terms of perceived emotions, preference, and beauty. Beauty ratings correlated strongly with sadness ratings $(r=.59, p<.001)$ but not with happiness ratings $(r=.16, n s)$, suggesting that

Music Perception volume 29, ISSUe 3, PP. 311-317. ISSN 0730-7829, ELECTRONIC ISSN 1533-8312. () 2012 BY THE REgENTS OF THE UNIVERSITY OF CALIfORNIA ALL RIGHTS RESERVED. PLEASE DIRECT ALL REQUESTS FOR PERMISSION TO PHOTOCOPY OR REPRODUCE ARTICLE CONTENT THROUGH THE UNIVERSITY OF CALIFORNIA PRESS'S RIGHTS AND PERMISSIONS WEBSITE, HTTP://WWW.UCPRESSJOURNALS.COM/REPRINTINFO.ASP.DOI: 10.1525/MP.2012.29.3.311 
aesthetic appreciation and beauty may play a significant role in the enjoyment of sad music.

To explore this intriguing possibility further, we asked simple questions: First, what kinds of subjective emotional experiences do sad music induce in listeners? Second, is the tendency to enjoy sad music associated with particular personality attributes? Because the complexity of emotional response was of particular concern, we used three sets of emotional rating scales representing different theories of emotion; discrete emotions, three-dimensional model, and the Geneva Emotional Music Scale, which is specifically designed to measure a wide range of musicinduced emotions (Zentner, Grandjean, \& Scherer, 2008).

If sad music indeed evokes complex, aesthetic emotions (see e.g., Scherer, 2004), such experiences may be especially appealing to individuals with certain personalities. The trait Openness to Experience is related to a sensitivity to art and beauty (McCrae \& Sutin, 2009), to a preference for diverse and complex music styles (e.g., Rentfrow \& Gosling, 2003), and to the experience of aesthetic chills in response to music (Nusbaum \& Silvia, 2011). The trait Empathy also has been implicated in vicarious responses to aesthetic experiences. In its broadest sense, Empathy is defined as an individual's responsivity to the observed experiences of another, involving both cognitive and affective components (Davis, 1980). Empathic distress has previously been associated with greater enjoyment of sad films (De Wied et al., 1994). Additionally, empathy and its "hot" subcomponent emotional contagion have also been mentioned as possible mechanisms through which music can induce emotions (Juslin \& Västfjäll, 2008). So our second question addressed whether Openness to Experience and Empathy were related to the enjoyment of sad music.

\section{Method}

\section{PARTICIPANTS}

The participants were 148 Finnish university students from different faculties aged 18-49 years (mean $=23.50$, $S D=4.84,77.08 \%$ females $)$.

\section{STIMULI AND MEASURES}

The stimuli were 16 film music excerpts ${ }^{1}$ with normatively verified emotional tone (four each of scary, happy, sad, and tender; see Appendix for the list of excerpts), ranging from 45 to $77 \mathrm{~s}$ in length $($ mean $=57.13, S D=$ 9.74). These excerpts were selected from a set of 110 with empirically established emotion and familiarity ratings

\footnotetext{
${ }^{1}$ Details relating to the stimuli (mean ratings and audio examples) can be found online at https://www.jyu.fi/music/coe/materials/emotion/ soundtracks-1min/
}

(Eerola \& Vuoskoski, 2011). In order to minimize the possibility of extramusical associations, only excerpts rated as unfamiliar were chosen for the present study. Longer versions of the original 15-s excerpts were taken and tested in a pilot experiment. Twelve participants (mean age $=24.67$ years, $S D=2.27,58.33 \%$ females) rated the emotions expressed by the excerpts using discrete emotion scales (sadness, happiness, anger, fear, and tenderness). Repeated measures ANOVAs and multiple comparisons of means (Tukey) confirmed that the excerpts conveyed the intended emotions (all post hoc comparisons were significant at .01 level).

The Big Five Inventory (BFI; John \& Srivastava, 1999) was used to assess the personality trait Openness to Experience. Empathy was assessed using the Interpersonal Reactivity Index (IRI; Davis, 1980), which taps into four separate aspects of the global concept of Empathy: Fantasy, Perspective-taking, Empathic Concern, and Personal Distress.

PROCEDURE

The listening experiments were conducted individually using a computer interface and studio quality headphones. The participants had filled in the BFI prior to the listening experiment, and the IRI was sent to the participants after the experiment. One hundred and thirty one participants $(88.51 \%)$ returned the IRI.

The participants received the following instructions: "Concentrate on listening to the music. After each music excerpt, evaluate what kinds of emotions the music evoked in you. The music may not necessarily evoke any emotions in you, so please try carefully to separate your own feelings from the emotions expressed by the music. First, rate the intensity of your emotional response in general, and then describe your felt emotion with the adjective scales below. You should also rate how much you liked each excerpt. After you have completed the ratings, you can move to the next excerpt by pressing 'next."'

There were four groups of participants. Group 1 ( $n=46)$ only evaluated the intensity of their emotional responses and how much they liked each excerpt. The other groups could also describe their potential emotional responses using different scales. Group $2(n=34)$ provided ratings for five discrete emotions (sadness, happiness, tenderness, fear, and anger). Group $3(n=35)$ provided ratings for six unipolar scales derived from the three-dimensional emotion model (positive and negative valence, high and low energy, and high and low tension; Schimmack \& Grob, 2000) and Group $4(n=33)$ for the nine scales of the music-specific GEMS-9 (wonder, transcendence, power, tenderness, nostalgia, peacefulness, joyful activation, sadness, and tension; 
Zentner et al., 2008). All ratings were done on scales from "1" ("not at all") to "7" ("very much").

\section{Results}

EMOTIONS EXPERIENCED IN RESPONSE TO SAD EXCERPTS

Repeated measures ANOVAs followed by multiple comparisons of means (adjusted by Tukey's method) were carried out to analyze the emotion ratings obtained with the discrete emotion and GEMS scales. In the case of discrete emotions, the ratings of experienced sadness (in response to sad excerpts) were significantly higher than the ratings of any other emotion: $F(4,132)=46.50, p<$ .001, $\eta_{\mathrm{G}}^{2}$ (generalized eta squared; Bakeman, 2005) = .46. All post hoc comparisons between sadness and other discrete emotions were significant at the .001 level. In the case of the GEMS model, the ratings of experienced sadness were significantly higher than those for all other emotions - except nostalgia: $F(8,256)=59.38, p<.001$, $\eta_{\mathrm{G}}^{2}=.53$. The post hoc comparisons between sadness and other GEMS scales (except nostalgia) were significant at the .001 level. Although the participants reported experiencing sadness more than any other emotion (in response to sad excerpts), other more complex and positive feelings - such as nostalgia, peacefulness, and wonder were also clearly evident in the ratings of the participants using the more nuanced GEMS scales. The mean GEMS ratings in response to sad excerpts are illustrated in Figure 1.

In order to determine whether the nuanced emotional responses to sad excerpts were experienced overall as positive or negative, we examined the valence ratings obtained with the three-dimensional emotion model. The ratings of positive valence were somewhat higher than the ratings of negative valence, but a two-tailed, paired $t$-test revealed that overall, the emotions evoked by sad excerpts were rated as neither negative nor positive, $t(34)=1.49, p=n s$. The mean ratings for positive and negative valence were $3.03(S D=1.83)$ and $2.48(S D=1.67)$, respectively. A similar analysis for scary excerpts yielded different results, as emotional responses to scary excerpts were rated as clearly unpleasant, $t(34)$ $=-4.11, p<.001$. The mean ratings for positive and negative valence were $2.12(S D=1.53)$ and $3.78(S D=$ 2.13). In comparison, the emotions evoked by tender and happy excerpts were rated as clearly pleasant, $t(34)=$ $11.98, p<.001$ and $t(34)=13.99 p<.001$, respectively.

\section{LIKING AND INTENSITY RATINGS FOR THE DIFFERENT} TYPES OF EXCERPTS

A repeated measures ANOVA and multiple comparisons of means were conducted to compare liking ratings for sad excerpts with liking ratings for the other types of excerpts (see Figure 2 for the mean liking and

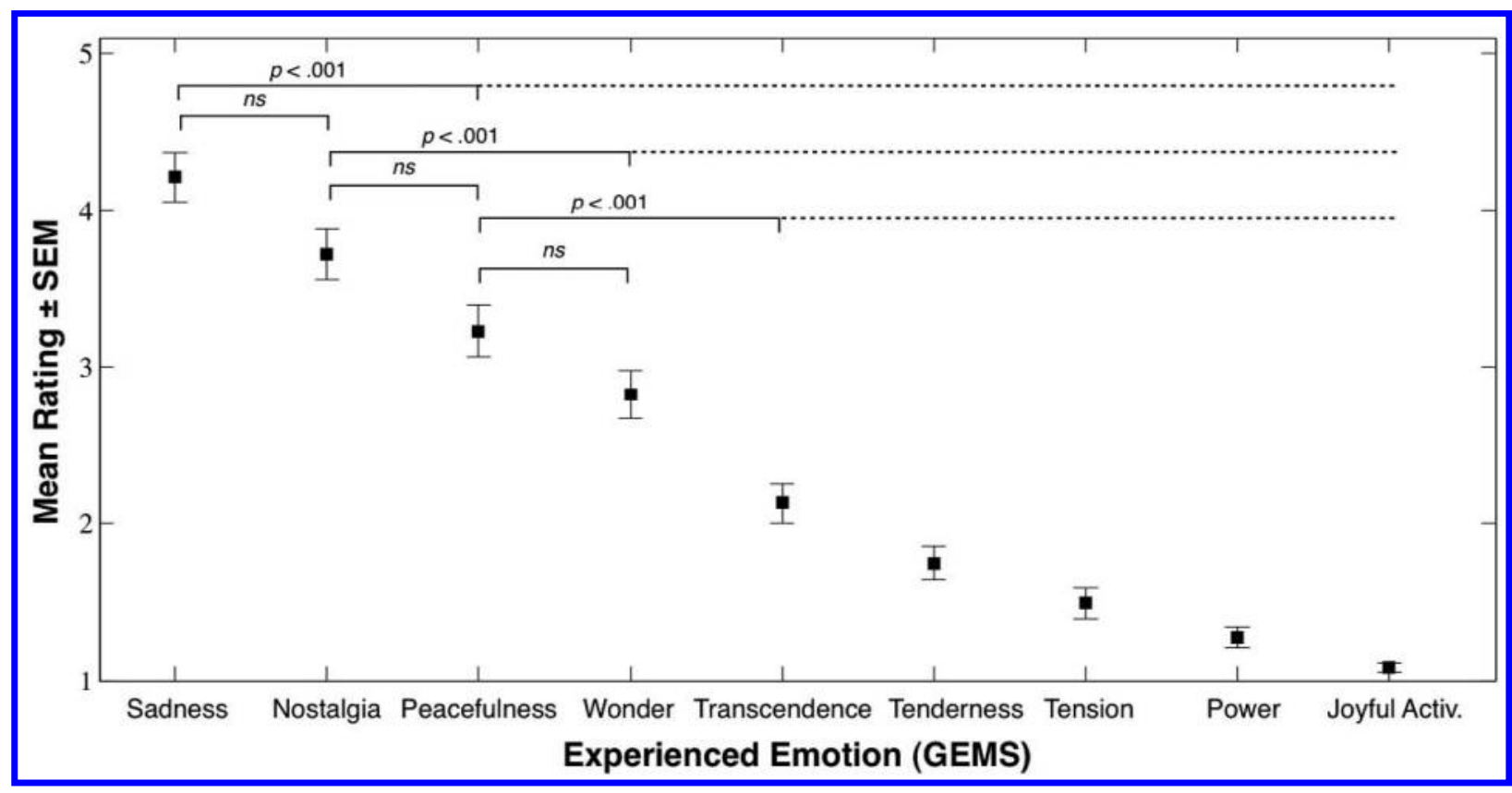

FIGURE 1. Mean GEMS ratings and standard errors for emotions experienced in response to sad excerpts, and the results of multiple comparisons of means (adjusted by Tukey's method). 


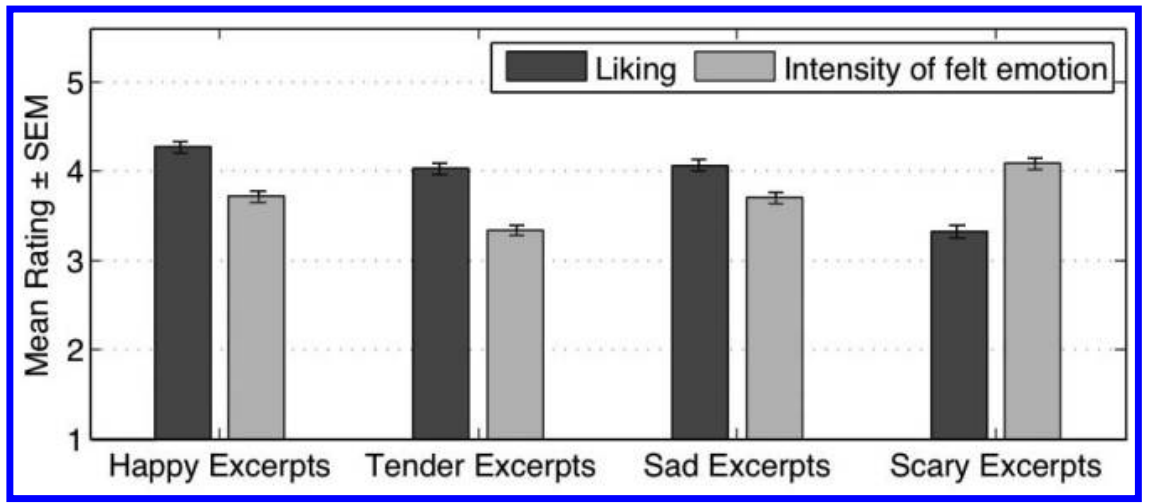

FIGURE 2. Mean ratings of liking and intensity of felt emotion (+ or - standard error of the mean) for the different types of excerpts.

intensity ratings for the different types of excerpts). There were no significant differences in the liking ratings for sad, happy, and tender excerpts, but scary excerpts were significantly less liked; $F(3,441)=37.47$, $p<.001, \eta_{\mathrm{G}}^{2}=.15$. The post hoc comparisons between scary excerpts and other types of excerpts were significant at the .001 level. However, scary excerpts also evoked the most intense emotional responses in the participants; $F(3,441)=27.96, p<.001, \eta_{\mathrm{G}}^{2}=.10$. The post hoc comparisons between scary and other types of excerpts were significant at the .001 level.

OPENNESS TO EXPERIENCE, EMPATHY, AND LIKING

FOR SAD EXCERPTS

Finally, we explored the question of whether the tendency to enjoy sad music is associated with particular personality traits. Correlation analysis, summarized in Table 1, revealed that both Openness to Experience and global Empathy were significantly connected with liking for sad excerpts, $r(146)=.21$ and $r(129)=.26$, both $p<.01$. As a control measure, we also investigated whether the traits correlated with liking for the other types of excerpts.

TABLE 1. Correlations Between Personality Factors and Mean Liking Ratings for the Different Types of Excerpts

\begin{tabular}{llrrl}
\hline & \multicolumn{4}{c}{ Mean Liking Ratings } \\
\cline { 2 - 5 } & Sad & Happy & Scary & Tender \\
\hline Openness to Experience & $.21^{* *}$ & -.04 & .12 & .14 \\
Global Empathy & $.26^{* *}$ & .01 & -.06 & $.32^{\star * *}$ \\
Fantasy & $.28^{* *}$ & .10 & .10 & $.34^{* *}$ \\
Perspective Taking & .09 & -.08 & -.14 & .15 \\
Empathic Concern & $.23^{* *}$ & .01 & -.13 & $.25^{* *}$ \\
Personal Distress & .05 & -.01 & .01 & .07 \\
\hline${ }^{*} p<.05,{ }^{* *} p<.01,{ }^{* * *} p<.001$ & & & &
\end{tabular}

Openness to Experience did not correlate with liking for scary, happy, or tender excerpts, but Empathy correlated with liking for tender excerpts, $r(129)=.32, p<.001$. A closer look at the four subscales of Empathy revealed that only two of the subscales - Fantasy and Empathic Concern - were significantly correlated with liking for sad music, $r(129)=.28$, and .23 , both $p<.01$. The Fantasy scale taps into the tendency to imaginatively transpose oneself into the feelings and actions of fictitious characters, while the Empathic Concern scale assesses the degree to which one experiences feelings of compassion and concern for others undergoing negative experiences (Davis, 1980).

Further analysis revealed that Openness to Experience and Fantasy also correlated with the intensity of emotions experienced in response to sad excerpts, $r(129)=.17$ and .19 , both $p<.05$. It should also be noted that the intensity of emotions experienced in response to sad excerpts correlated strongly with liking ratings, $r(146)=.57, p<.001$, suggesting a link between intensity of felt emotion and liking. Global Empathy and Openness to Experience were also related to experienced positive valence in response to sad excerpts, $r(33)=.38, p<.05$ and $r(33)=.32, p=.065$, which further suggests that those who are empathetic and "open" experience greater enjoyment in response to sad music.

\section{Discussion}

Our results uncover the complexity of emotional responses to sad music, showing they are not experienced as negative or unpleasant, unlike most experiences of sad real-life events. Although sadness was the most salient emotion experienced (in response to sad excerpts), other emotions such as nostalgia, peacefulness, and wonder were also clearly evident. These other emotions can be characterized as positive and pleasurable (see Zentner et al., 2008). Our results suggest that the enjoyment of sad 
music cannot be fully explained by the dissociation theory (Garrido \& Schubert, 2011; Schubert 1996), as the emotional responses to scary excerpts were certainly rated as unpleasant. If dissociation from pain and displeasure should indeed take place in an aesthetic context, it does not explain why sad music is enjoyed while scary music is not. Instead, we propose that the enjoyment of sad music may stem from an intense emotional response combined with the aesthetic appeal of sad music. Three findings support this interpretation. First, sad music evoked, in addition to sadness, a range of positively toned, aesthetic emotions (see e.g., Scherer, 2004; Zentner et al., 2008). Second, those most able to appreciate aesthetic experiences and beauty - those highest in the trait Openness to Experience - most liked sad music. Third, those who experienced the most intense emotions in response to sad music - including participants scoring high in the trait Empathy - also enjoyed sad music the most.

Although scary music induced the most intense emotional responses in listeners, those responses were rated as significantly unpleasant. Evidence from previous studies suggests that the most evident difference between sad and scary music is related to their aesthetic appeal. In a study of 110 music excerpts (Eerola \& Vuoskoski, 2011), ratings of perceived sadness had a high positive correlation with ratings of perceived beauty $(r=.59, p<$ .001 ), while fear and anger ratings had high negative correlations with beauty ratings $(r=-.73$ and $r=-.56$ both $p<.001)$. However, it should be noted that aesthetic responses are highly subjective (for a recent discussion on aesthetic responses to music, see Huron, 2009), and thus it is possible that only some people find sad music beautiful, or scary music ugly.

Our interpretation is consistent with the findings though not with the conclusions - of Garrido and Schubert (2011), who found that Absorption (but not clinical Dissociation) and Music Empathizing were reliable predictors of the enjoyment of sad music. Our results suggest that - as in the case of tragic films (De Wied et al., 1994) - sad music may induce stronger emotional responses in empathic listeners, which in turn leads to greater enjoyment. This may also be the case for listeners scoring high on Absorption, as Absorption has previously been associated with stronger felt emotions (and felt sadness in particular) in response to music (Kreutz, Ott, Teichmann, Osawa, \& Vaitl, 2008), and it is also related to a tendency to empathize with objects of attention (Tellegen \& Atkinson, 1974). Other studies have also found that Absorption and Openness to Experience are highly correlated traits, reflecting a similar tendency to appreciate aesthetic experiences and fantasize (Glisky, Tataryn, Tobias, Kihlstrom, \& McConkey, 1991; Wild, Kuiken, \& Schopflocher, 1995). The dissociation theory also implies that the sadness induced by sad music is different from sadness experienced in everyday life. However, a recent study suggests that sad music can induce similar changes in memory and judgment as the recollection of a sad autobiographical event - especially in empathic listeners (Vuoskoski \& Eerola, in press). Further, a number of studies using music as a method of mood manipulation suggest that musically induced affective states are linked with similar behavioral and cognitive changes as those produced by affective states experienced in everyday life (for reviews, see Västfjäll, 2002, 2010).

In summary, the enjoyment of sad music cannot be entirely explained by the dissociation theory (Garrido \& Schubert, 2011; Schubert, 1996), as it does not account for the divergent responses to music expressing different negative emotions. The dominant emotion evoked by sad music appears to be interpreted as sadness by the listeners, but such music also evokes a range of more positive, aesthetic emotions. Sad music appealed most to those who have a heightened responsiveness to the experiences of others, who experience intense emotions in response to sad music, and who show enhanced sensitivity to art and beauty.

\section{Author note}

Correspondence concerning this article should be addressed to Jonna K. Vuoskoski, Finnish Centre of Excellence in Interdisciplinary Music Research, P. O. Box 35 (M), FI-40014 University of Jyväskylä, Finland. E-MAIL: jonna. vuoskoski@jyu.fi

\section{References}

BAKEMAN, R. (2005). Recommended effect size statistics for repeated measures designs. Behavior Research Methods, 37, 379-384.

DAVIS, M. H. (1980). A multidimensional approach to individual differences in empathy. JSAS Catalog of Selected Documents in Psychology, 10, 85.
De Wied, M., Zillmann, D., \& Ordman, V. (1994). The role of empathic distress in the enjoyment of cinematic tragedy. Poetics, 23, 91-106.

$\rightarrow$ Eerola, T., \& Vuoskoski, J. K. (2011). A comparison of the discrete and dimensional models of emotion in music. Psychology of Music, 39, 18-49. 
$\rightarrow$ GARrido, S., \& Schubert, E . (2011). Individual differences in the enjoyment of negative emotion in music: A literature review and experiment. Music Perception, 28, 279-296.

$\rightarrow$ Glisky, M. L., Tataryn, D. J., Tobias, B. A., Kinlstrom, J. F., \& MCCONKEY, K. M. (1991). Absorption, openness to experience, and hypnotizability. Journal of Personality and Social Psychology, 60, 263-272.

Huron, D. (2009). Aesthetics. In S. Hallam, I. Cross, \& M. Thaut (Eds.), The Oxford handbook of music psychology (pp. 151-159). Oxford, UK: Oxford University Press.

John, O. P., \& SRivastava, S. (1999). The Big Five trait taxonomy: History, measurement, and theoretical perspectives. In L. A. Pervin \& O. P. John (Eds.), Handbook of personality: Theory and research (pp. 102-138). New York: Guilford Press.

Juslin, P. N., \& VÄSTfJÄLL, D. (2008). Emotional responses to music: The need to consider underlying mechanisms. Behavioral and Brain Sciences, 31, 559-575.

KIvY, P. (1990). Music alone: Philosophical reflections on the purely musical experience. Ithaca, NY: Cornell University Press.

Kreutz, G., Ott, U., Teichmann, D., Osawa, P., \& Vaitl, D. (2008). Using music to induce emotions: Influences of musical preference and absorption. Psychology of Music, 36, 101-126.

$\rightarrow$ Kreutz, G., Schubert, E., \& Mitchell, L. A. (2008). Cognitive styles of music listening. Music Perception, 26, 57-73.

LEVINSON, J. (1997). Music and negative emotion. In J. Robinson (Ed.), Music and meaning (pp. 215-241). Ithaca, NY: Cornell University Press.

McCrae, R. R., \& Sutin, A. R. (2009). Openness to experience. In M. R. Leary \& R. H. Hoyle (Eds.), Handbook of individual differences in social behavior (pp. 257-273). New York: Guilford.

$\rightarrow$ Nusbaum, E. C., \& Silvia, P. J. (2011). Shivers and timbres: Personality and the experience of chills from music. Social Psychological and Personality Science, 2, 199-204. $\rightarrow$ Rentfrow, P. J., \& Gosling, S. D. (2003). The do re mi's of everyday life: The structure and personality correlates of music preferences. Journal of Personality and Social Psychology, 84, $1236-1256$

$\rightarrow$ Robinson, J. (1994). The expression and arousal of emotion in music. The Journal of Aesthetics and Art Criticism, 52, 13-22.

$\rightarrow$ SCHERER, K. R. (2004). Which emotions can be induced by music? What are the underlying mechanisms? And how can we measure them? Journal of New Music Research, 33, 239-251.

$\rightarrow$ Schimmack, U., \& Grob, A. (2000). Dimensional models of core affect: A quantitative comparison by means of structural equation modelling. European Journal of Personality, 14, 325-345.

$\rightarrow$ SCHUbert, E. (1996). Enjoyment of negative emotions in music: An associative network explanation. Psychology of Music, 24, 18-28.

$\rightarrow$ Tellegen, A., \& Atkinson, G. (1974). Openness to absorbing and self-altering experiences (" absorption"), a trait related to hypnotic susceptibility. Journal of Abnormal Psychology, 83, 268-277.

Vuoskoski, J. K., \& Eerola, T. (in press). Can sad music really make you sad? Indirect measures of affective states induced by music and autobiographical memories. Psychology of Aesthetics, Creativity, and the Arts.

VÄstFJÄLL, D. (2002). Emotion induction through music: A review of the musical mood induction procedure. Musicae Scientiae, Special issue 2001-2002, 173-209.

VÄSTFJÄLL, D. (2010). Indirect perceptual, cognitive, and behavioural measures. In P. N. Juslin \& J. A. Sloboda (Eds.), Handbook of music and emotion: Theory, research, applications (pp. 255-278). Oxford, UK: Oxford University Press.

$\rightarrow$ Wild, T. C., Kuiken, D., \& SCHOPflocher, D. (1995). The role of absorption in experiential involvement. Journal of Personality and Social Psychology, 69, 569-579.

$\rightarrow$ Zentner, M., Grandjean, D., \& Scherer, K. (2008). Emotions evoked by the sound of music: Characterization, classification, and measurement. Emotion, 8, 494-521. 


\begin{tabular}{|c|c|c|c|c|c|c|}
\hline Excerpt & Emotion & Soundtrack name & Track & Time & Duration & $\begin{array}{l}\text { Number } \\
\text { in the set } \\
\text { of } 110^{* *}\end{array}$ \\
\hline F1 & Scary & The Alien Trilogy & 9 & $00: 00-00: 56$ & $56 \mathrm{~s}$ & 003 \\
\hline $\mathrm{F} 2$ & Scary & Batman Returns & 5 & $00: 00-00: 46$ & $46 s$ & 011 \\
\hline F3 & Scary & The Fifth Element & 17 & 00:00-01:01 & $61 \mathrm{~s}$ & 018 \\
\hline $\mathrm{F} 4$ & Scary & The Alien Trilogy & 11 & 02:04-02:58 & $54 \mathrm{~s}$ & 091 \\
\hline $\mathrm{H} 1$ & Happy & Oliver Twist & 8 & 01:32-02:09 $\mathrm{L}^{*}$ & $72 \mathrm{~s}$ & 027 \\
\hline $\mathrm{H} 2$ & Happy & Dances with Wolves & 10 & 00:00-00:46 & $46 \mathrm{~s}$ & 055 \\
\hline $\mathrm{H} 3$ & Happy & The Untouchables & 6 & 01:26-02:06 L $\mathrm{L}^{*}$ & $67 \mathrm{~s}$ & 071 \\
\hline $\mathrm{H} 4$ & Happy & Pride \& Prejudice & 4 & 00:10-01:06 & $56 \mathrm{~s}$ & 105 \\
\hline S1 & Sad & The English Patient & 18 & 00:00-00:59 & $59 \mathrm{~s}$ & 031 \\
\hline S2 & Sad & The Portrait of a Lady & 9 & 00:00-00:23 L $\mathrm{L}^{*}$ & $45 \mathrm{~s}$ & 033 \\
\hline S3 & Sad & Running Scared & 15 & $01: 45-02: 40$ & $55 \mathrm{~s}$ & 086 \\
\hline S4 & Sad & Pride \& Prejudice & 13 & $00: 40-01: 30$ & $50 \mathrm{~s}$ & 109 \\
\hline $\mathrm{T} 1$ & Tender & The Portrait of a Lady & 3 & 00:23-01:08 & $45 \mathrm{~s}$ & 029 \\
\hline $\mathrm{T} 2$ & Tender & Shine & 10 & 01:01-02:00 & $59 \mathrm{~s}$ & 041 \\
\hline T3 & Tender & Pride \& Prejudice & 1 & 00:10-00:49 L $\mathrm{L}^{*}$ & $77 \mathrm{~s}$ & 042 \\
\hline $\mathrm{T} 4$ & Tender & The Godfather III & 5 & 01:13-02:19 & $66 s$ & 107 \\
\hline
\end{tabular}

${ }^{*} \mathrm{~L}=$ looped

${ }^{*}$ see the list of stimuli for the set of 110 excerpts, Eerola \& Vuoskoski (2011) 